www.jmscr.igmpublication.org

Impact Factor 5.84

Index Copernicus Value: 83.27

ISSN (e)-2347-176x ISSN (p) 2455-0450

crossref DOI: _https://dx.doi.org/10.18535/jmscr/v5i3.104

Journal Of Medical Science And Clinical Research

\title{
Comparative Evaluation of Efficacy \& Safety of Intravenous Labetalol and Oral Nifedipine in Severe Hypertension of Pregnancy
}

\author{
Authors \\ Dr Dibya Singh, Dr Shikha Singh, Prof. Saroj Singh, Dr Rekha Rani, \\ Dr Urvashi Vrema, Dr Ashwini Kumar Nigam, Dr Neeraj Yadav \\ Dept. of Obstetrics \& Gynaecology SNMC Agra India \\ Email:drds.31080@gmail.com
}

\begin{abstract}
Objective: Comparative evaluation of efficacy of intravenous labetalol and oral nifedipine in severe hypertention in pregnancy.

Design: Prospective Randamised trial

Setting: S.N. medical college, Agra

Population: Pregnant women with severe hypertension $\geq 160 / 110 \mathrm{mmHg}$ who required immediate treatment.

Methods: Patients were randomised using random table in to two groups. Group A:40 patients received intravenous labetalol injection(in escalating dose regime 20,40,80,80 and $80 \mathrm{mg}$ ).Group B:40 patients received oral Nifedipine (in escalating doses 10, 20,20,20 and 20mg)every 20 minutes until the target blood pressure of $\leq 160 / 110 \mathrm{mmHg}$ was achieved or maximum 5 doses used. MAIN OUTCOME MEASURE The time taken to achieve a blood pressure of $\leq 160 / 110 \mathrm{mmHg}$ and doses required.

Results: 38(95\%)/40 in labelalol group \& 40/40 in nifedipine group showed control of adequate control of blood pressure. Difference is not significant(0.331)The median time taken to achieve target blood pressure was $29.5+11.8$ and $43.68+16.7$ minutes for nifedipine and labetalol, respectively $(P=0.00007)$. Mean systolic and diastolic blood pressure reduction with nifedipine at after first dose was $17.03+7.36 \mathrm{mmhg}$ and $10.75+6.87 \mathrm{mmhg}$ respectively. Mean systolic and diastolic blood pressure reduction with labetalol after first dose was 13.65+5.37 mmhg and 8.6+3.23mmhg respectively. Average no. of doses required with labetalol was significantly more $(p=0.00005)$ than nifedipine. There was no significant difference between both the groups regarding systolic $(p=0.465)$ and diastolic $(p=0.08)$ blood pressure at 24 hours after control of blood pressure.
\end{abstract}

Conclusions: Both drugs effectively control blood pressure in severe hypertention in pregnancy.

Keywords: Preeaclampsia, Labetalol,Nifedipine.

\section{Introduction}

How pregnancy incites or aggravates hypertension remains unsolved despite decades of intensive research, hypertensive disorders remain among the most significant and intriguing unsolved problems in obstetrics. ${ }^{1}$ According to WHO hypertensive disorders of pregnancy affect about $10 \%$ of all pregnant women around the world. ${ }^{2,3}$ It was estimated that deaths due to hypertensive disorders of pregnancy represents $13 \%$ of all maternal deaths. ${ }^{4}$ Among hypertensive disorders that complicate pregnancy, pre-eclampsia and 
eclampsia stand out as major cause of maternal and perinatal mortality and morbidity. Preeclampsia is a syndrome defined by hypertension and proteinuria that may be associated with myriad other signs and symptoms such as edema, visual disturbances, headaches and epigastric pain, laboratory abnormalities may include hemolysis elevated liver enzymes and low platelet counts (HELLP Syndrome). ${ }^{5}$

Antihypertensives are integral part of management. The two main goals of management of women with preeclampsia are control of hypertension and prevention of seizures (ACOG 2002). Various studies done for different antihypertensive drugs compared for the treatment of severe hypertension in pregnancy concluded that there is insufficient data to favour one agent over another and agents other than parenteral hydralazine (eg parenteral labetalol or oral nifedipine) are preferable because of reduced maternal and fetal adverse effects (American heart association 2008). According to a randomize clinical trial done at JIPMER Puducherry both oral nifedipine and intravenous labetalol are effective in the treatment of hypertensive crisis. Intravenous labetalol may have benefits because it is more effective in reducing the SBP, DBP and MAP to target levels with a lower number of doses. ${ }^{6}$

Another randomized trial of intravenous labetalol and oral nifedipine in severe pregnancy induced hypertension concluded oral nifedipine \& intravenous labetalol regimes are effective in the management of severe hypertention in pregnancy ; howerever nifedipine controls hypertension more rapidly\& is associated with a significant increase in urinary output. ${ }^{7}$

A double blind randomized trial done at university of Malaya, Malasia says oral nifedipine and intravenous labetalol regimes are similarly effective in the control of severe hypertension in pregnancy. ${ }^{8}$

Still Nifedipine is not currently approved for acute severe hypertension in pregnancy by the American College of Obstetricians and Gynaecologists. ${ }^{9}$
In India, however the intravenous labetalol has been available only recently and therefore its use in India during pregnancy is still to be reported and checked. With the given circumstances, the search for an ideal antihypertensive agent in pregnancy was done......

\section{Method and Material}

The study was conducted in the Department of Obstetrics and Gynaecology, Sarojini Naidu Medical College, Agra during the period from October 2011 to September 2013. Patients were selected from labour room and outpatient department according to the criteria. 80 patients were included in the study. Inclusion criteria were pregnancy more than or equal to 34 week of gestation having severe hypertension at first instance of detection of hyperrtension (Age 18 to 35 years) either in labour or not in labour, systolic blood pressure of at least $160 \mathrm{mmHg}$ or diastolic blood pressure at least $110 \mathrm{mmHg}$ with or without proteinuria, no absolute contraindication for labetalol. Exclusion Criteria were patients with cardiogenic shock, cardiac failure,patients with bronchial asthma, pulmonary edema, chronic obstructive pulmonary disease, patients with bradycardia $(\mathrm{PR}<60$ beats/min),H/o renal pathology, H/o essential hypertension, patients with allergic diathesis.

All the patients were subjected to detailed history, examination and lab investigations (CBC,LFT, RFT,PT/APTT,URINE ROUTINE). All the patients were kept on strict urine output monitoring. Fundus examination was done by specialist. All patients received loading dose of $\mathrm{MgSo} 4$ for Seizure prophylaxis. Cardiotocography and ultrasound scan for fetal well being was done. Randomised prospective comparative trial was done. Once the patients were enrolled, vitals signs were recorded every 30 minutes, including blood pressure measurement by a mercury columns sphygmomanometer. All 80 patients were devided in two groups of 40 each. Group A-Patients with blood pressure $\geq 160 / 110 \mathrm{mmHg}$ received 5 doses of intravenous labelatel 20 minutes apart of dosing 
20mg, 40mg, 80mg, 80mg,80mg. End point of trial was if the therapeutic goal of $\leq 160 / 110$ $\mathrm{mmHg}$ was achieved or a maximum of 5 doses (i.e. 1 h 20 min).Group B- Patient with blood pressure $\geq 160 / 110 \mathrm{mmHg}$ received 5 doses of oral nifedipine 20 minutes apart of dosing $10 \mathrm{mg}$, $20 \mathrm{mg}, 20 \mathrm{mg}, 20 \mathrm{mg}, 20 \mathrm{mg}$. End point of the trial was if the therapeutic goal of BP $\leq 160 / 110 \mathrm{mmHg}$ was achieved or a maximum of 5 doses.(i.e. at $1 \mathrm{~h}$ $20 \mathrm{~min}$ ). Primary outcome measure was assessed in terms of control of the blood pressure $\leq 110 \mathrm{~mm}$ $\mathrm{Hg}$ diastolic and $\leq 160 \mathrm{~mm} \mathrm{Hg}$ systolic blood pressure. Patients were monitered till delivery $/ 48$ hours after control of blood pressure and followed up till 3 weeks after delivery. The secondary outcome were in terms of-continuation of pregnancy, mode of delivery-vaginal/lower segment caesarean section,period of gestation at the time of delivery, eclampsia, abruptioplacentae, LVF, cerebralhaemorrhage, hyperpyrexia, DIC, renal failure, hospital stay of mother. Side effects were noted like: Bradycardia $(<60 / \mathrm{min})$, Tachycardia (>100/min), Blurring, Flushing, Headache, Drowsiness, Diarrhoea Wheezing, Fever. Perinatal outcomes in terms of: Baby weight, Apgar score, Maturity, Need for Neonatal intensive care unit admission, Need for ventilation, Hypoglycemia, RDS, Septicemia, Hospital stay of the baby, Perinatal mortality.

\section{Results}

The demographic and clinical profiles of the women in both groups were comparable (Table I). There was no patient of severe hypertension of less than 34 weeks of pregnancy (Table II). In the labetalol group 37(92.50\%) out of the 40 patients were unbooked ones and other 3 booked patients had first onset of severe hypertension at 38 weeks(undergone lower segment caesarean section within 6 hours) and 38,39 weeks(patient was in labour and delivered within 2 hours) In the nifedipine group $35(87.50 \%)$ out of 40 patients were unbooked and had come to the hospital for the first time with severe hypertension and other five booked patients had first onset of severe hypertension at $34,34,34,36,36$ weeks(four were induced and delivered within 10 hours and one had undergone caesarean section)(Table III). In $38(95 \%)$ out of 40 patients in labetalol, the blood pressure was controlled adequately i.e. in the first 2 hours by the doses described earlier. In nifedipine group, all 40 (100\%) patients were controlled within first 2 hours. There was no significant difference between the two groups ( $p=$ 0.493)(Table IV).The patients not controlled with intravenous labetalol was controlled with intravenous nitroglycerine (NTG) drip and their lower segment caesarean section was done within three hours. In labetaolol group, only 8 patients (20\%) achieved control of hypertension below the desired level with one dose whereas nifedipine achived desirable control with only one dose in 20 patients $(50 \%)$. There was significant difference between the two groups $(\mathrm{p}=0.004)$, significant. However labetalol was useful in controlling 38/40 (95\%) patients with larger dose.(Table V). Although there was significant difference between the two groups $(\mathrm{p}=0.00007)$ regarding time to achieve the blood pressure goal. It was significantly shorter with nifedipine group and average dose required with labetalol was significantly more $(\mathrm{p}=0.00005)$ than with nifedipine, 24 hours after control of blood pressure, no significant difference was found between group $A$ and Group $B(p=0.465$ for systolic and $\mathrm{p}=0.0876$ for diastolic blood pressure). Nifedipine group had more urine output than labetalol group. There was significant difference between the two groups $(\mathrm{p}=0.0001)$.

(Table VI). There were some minor side effects mentioned above with significant difference only with tachycardia $(\mathrm{p}=0.025)$ and flushing $(\mathrm{p}=0.02)$ in group (Table VII). There was no case of over shoot hypotension in both the groups $(<90 / 60$ $\mathrm{mmHg}$ ). No significant difference was found regarding perinatal outcome (Table VIII). 
Table - I : Patients Profile

\begin{tabular}{|l|l|c|c|}
\hline 1. & Age (Years) & Group A (Labetalol) & Group B (Nifedipine) \\
\hline & Mean & $25.3 \pm 3.96$ & $25.87 \pm 3.85$ \\
\hline 2. & Parity : & & \\
\hline & P0 & $25(62.50 \%)$ & $22(55.0 \%)$ \\
\hline & P1 & $11(27.50 \%)$ & $9(22.50 \%)$ \\
\hline & $>$ P1 & $4(10.0 \%)$ & $9(22.50 \%)$ \\
\hline 3. & Booked / Un-booked : & $3(7.50 \%)$ & \\
\hline & Booked & $37(92.50 \%)$ & $5(12.50 \%)$ \\
\hline & Un-booked & & $35(87.50 \%)$ \\
\hline
\end{tabular}

Table - II Period of Gestation in Weeks at the Time of Diagnosis of Severe Hypertension During the Pregnancy

\begin{tabular}{|l|c|c|c|c|}
\hline & $34-35$ & $36-37$ & $>37$ & Total \\
\hline Group A (Labetalol) & 8 & 22 & 10 & 40 \\
\hline Group B (Nifedipine) & 11 & 26 & 3 & 40 \\
\hline
\end{tabular}

Table - III: Time Interval between the Onset of Severe Hypertension and Delivery.

\begin{tabular}{|l|c|c|c|c|}
\hline & $<24$ hours & $\begin{array}{c}24 \text { hours-48 } \\
\text { hours }\end{array}$ & $>48$ hours & Total \\
\hline Group A (Labetalol) & 40 & 0 & 0 & 40 \\
\hline Group B (Nifedipine) & 39 & 1 & 0 & 40 \\
\hline
\end{tabular}

Table - IV : $\quad$ Control of Blood Pressure in the two Groups

\begin{tabular}{|l|l|l|l|}
\hline & Not Adequate & Adequate & Total \\
\hline Group A (Libetalol) & $2(5 \%)$ & $38(95 \%)$ & $40(100 \%)$ \\
\hline Group B (Nifedipine) & $0(0 \%)$ & $40(100 \%)$ & $40(100 \%)$ \\
\hline
\end{tabular}

Table - V : Distribution of Patients Showing The Number of Doses Required in the two Groups.

\begin{tabular}{|l|c|c|c|c|c|c|}
\hline & 1 dose & 2 doses & 3 doses & 4 doses & 5 doses & Total \\
\hline $\begin{array}{l}\text { Group A } \\
\text { (Libetalol) }\end{array}$ & $\begin{array}{c}8 \\
(20 \%)\end{array}$ & $17(42.50 \%)$ & $11(27.50 \%)$ & $2(5 \%)$ & $2(5 \%)$ & $40(100 \%)$ \\
\hline $\begin{array}{l}\text { Group B } \\
\text { (Nifedipine) }\end{array}$ & $20(50 \%)$ & $19(47.50 \%)$ & $1(2.50 \%)$ & $0(0 \%)$ & $0(0 \%)$ & $40(100 \%)$ \\
\hline
\end{tabular}

Table - VI

\begin{tabular}{|l|c|c|c|}
\hline & Group A (Labetalol) & Group B (Nifedipine) & P value \\
\hline Time to control Blood Pressure & $43.68 \pm 16.67$ & $29.5 \pm 11.8$ & 0.00007 \\
\hline No of Doses & $2.33 \pm 1.02$ & $1.53 \pm 0.55$ & 0.00005 \\
\hline $\begin{array}{l}24 \text { hour contol of blood } \\
\text { pressure }\end{array}$ & $141 \pm 6.56$ (systolic) & $142 \pm 5.58$ (systolic) & 0.465 \\
\hline Urine output(per hour) & $92.1 \underline{+5.14(\text { diastolic) }}$ & $90.1 \pm 5.2$ (diastolic) & 0.087 \\
\hline
\end{tabular}

Table - VII: Side Effects of the Drugs

\begin{tabular}{|l|c|c|}
\hline & Group A (Labetalol) & Group B (Nifedipine) \\
\hline Bradycardia $(<60 \mathrm{bpm})$ & 1 & 0 \\
\hline Tachycardia $(>100 \mathrm{bpm})$ & 2 & 10 \\
\hline Flushing & 0 & 6 \\
\hline Headache & 1 & 5 \\
\hline Drowsiness & 3 & 2 \\
\hline Diarrhoea & 1 & 1 \\
\hline Dyspnea & 2 & 0 \\
\hline Abnormal Vision & 0 & 0 \\
\hline Wheezing & 0 & 0 \\
\hline Fever & 1 & 0 \\
\hline
\end{tabular}


Table - VIII : Fetal Outcomes Showing Birth Weight, Period of Gestation at the Time of Delivery, Apgar Score, Preterm, Need for Ventilator, Hypoglycemia, Respiratory Distress Syndrome, Septicemia, Hospital Stay of The Baby.

\begin{tabular}{|l|c|c|}
\hline & Group A (Labetalol) & Group B (Nifedipine) \\
\hline BW (gms) & $2600 \pm 270$ & $2600 \pm 240$ \\
\hline POGD (Wks) & $36.5 \pm 1.20$ & $36.25 \pm 1.05$ \\
\hline PT & 22 & 20 \\
\hline NV & 4 & 3 \\
\hline AS(At $1,5,10 \mathrm{~min})$ & $7.2,8.2 .9 .4$ & $7.4,8.3,9.6$ \\
\hline HG & 2 & 0 \\
\hline RDS & 0 & 0 \\
\hline SP & 0 & 0 \\
\hline HS (Days) & $0.92 \pm 1.49$ & $0.82 \pm 1.41$ \\
\hline PNMR & 1 & 1 \\
\hline
\end{tabular}

\section{Discussion}

Treatment of severe hypertension in pregnancy is mandatory as it decreases the incidence of intracranial hemorrhage; hypertensive encephalopathy and maternal mortality. Worldwide, preeclampsia and eclampsia probably account for more than 50,000 maternal deaths a year ${ }^{10}$. According to the consensus report on high blood pressure the ideal antihypertensive drug should be potent, safe, rapidly acting, titratable and without having detrimental maternal or fetal side effects. All antihypertensive drugs affect both the mother and the fetus ; some may produce side effects in the mother and other may produce adverse effects on the fetus or the newborn ${ }^{11}$. In India, oral form of labetalol was available from eighties onwards but intravenous form of labetalol which is useful for the treatment of severe hypertension was not available till recently. Labetalol is a combined blocker of alpha-1 and non selective competitive beta adrenergic receptors with some intrinsic activity at $\beta_{2}$-adrenengic receptor,a very useful drug in the treatment of severe hypertension in pregnancy with quick onset and prolonged effect, no relfex tachycardia, no decrease in uteroplacental perfusion, an antiplatelet aggregation action, a thromboxane reducing effect, fetal lung maturation accelerating influence. It reduces cerebral perfusion pressure without reducing cerebral perfusion primarily by a decrease in systemic blood pressure. This makes it an ideal agent for blood pressure control in severely hypertensive pregnant women ${ }^{12}$ Nifedipine, a dihydropyridine (L-type) calcium channel blocker acutely lowers blood pressure by reducing calcium influx, calcium concentrations and peripheral resistance. It was mainly used for tocolysis in preterm labour, found to be safe and effective in the treatment of severe hypertension in pregnancy, increases cardiac index ${ }^{13}$, causes no changes in doppler indices of umbilical or uterine artery blood flow improves intrarenal haemodynamics with diuretic effect, inhibits platelet aggregation and thomboxane synthesis. Earlier on, there was apprehension in nifedipine use as the sublingual variety caused more sudden decrease in blood pressure, resulting thereby in overshoot hypotension and ischaemia thereupon ${ }^{14,15}$. The oral variety does not seem to have this. In our study it seems that nifedipine quickly reduces the blood pressure as average time to control blood pressure between two groups are with value of $43.68 \pm 16.67$ minutes and $29.5 \pm 11.8$ minutes $(\mathrm{p}=0.00007)$ for labetalol and nifedipine groups respectively which is statistically significant. Dhali et al (2012) found similar results regarding average control of blood pressure with value of $48.4 \pm 23.5$ minutes for labetalol group and $28.2 \pm 11.7$ minutes $(p=0.001)$ for nifedipine group.IA Raheem et all (2011) differ from this result as they found average time to reach target blood pressure $46 \pm 30$ minutes and $54 \pm 42$ minutes for nifedipine and labetalol group respectively with no significant diference $(\mathrm{p}=0.45)$. Regarding the control of blood pressure, nifedipine achieved adequate control of blood pressure with only one 
dose in 20/40(50\%) patients whereas in labetalol group, only $8 / 40(20 \%)$ patients achieved the control with one dose which was significant $(\mathrm{p}=$ 0.03).Nifedipine is also found to be having quick reduction of BP with fewer doses without having significant side effects in our study.Average number of doses required for control of blood pressure is significantly more for labetalol $(2.33 \pm 1.02) \quad$ than nifedipine $(1.53 \pm 0.55$ $\mathrm{p}=0.00005)$. Similar result was found by Dhali et all $(2012)(3.5 \pm 0.5$ for nifedipine $v / s \quad 4.5 \pm 1.5$ for labetalol $\mathrm{p}=0.001)$.IA Raheem et all(2010) differ from this result as they did not found significant difference $(p=0.60)$ between the doses for control of blood pressure. However nifedipine and labetalol both were effective for control of severe hypertension of pregnancy. The mean urine output of labetalol and nifedipine groups were $53.50 \pm 4.70$ and $66.75 \pm 7.03$ millitre/hour respectively after starting the drug (significant, $p$ $=0.0001)$. Nifedipine group had more urine output than labetalol group.Similar result was found by Dhali et all(2012) with $\mathrm{p}=0.001$ between the groups. There were 2 patients who had tachycardia in labetalol group and 10 patients in nifedipine group which is statistically significant $(\mathrm{p}=0.0252)$,it shows that nifedipine increases the heart rate., there was 1 case of bradycardia of the mother in the labetalol $\operatorname{group}(\mathrm{p}=1.0$ not significant). In the Scado et al(1999) study,an insignificant increase in heart rate with nifedipine $(\mathrm{P}=.147)$ and a significant decrease with labetalol $(\mathrm{P}=$. 034) were noted. There was minor side effects of the drugs, seen in our patients. Our patients tolerated the drugs well. Minor side effects like diarrhoea, headache etc, were there.. There was no case of overshoot hypotension, cardiac failure, maternal mortalities in both the groups. The mean birth weight of labetalol and nifedipine group was $2600 \pm 270$ and $2600 \pm 240$ grams respectively (not significant, $\mathrm{p}=0.999$ ). IA Raheem et al(2011) found that mean birth weight of neonates was $2.9 \mathrm{~kg}(2.2-3.1)$ for nifedipine group and $2.9 \mathrm{~kg}(2.7-3.2)$ for labetalol group with insignificant difference $(\mathrm{p}=0.95)$. The fetal outcome parameters in both the groups were comparable. There was 13 neonatal admissions in nursery in labetalol group and 20 admission in nifedipine group $(\mathrm{p}=0.1726$, no significant difference) for preterm and respiratory distress etc, but there was one case of perinatal morality in each both the groups.In study of IA Raheem (2011) ther were three neonatal intensive care admissions inboth the study groups.

\section{Conclusion}

Both drugs effectively (95\% labetalol and 100\% nifedipine) controlled the blood pressure in severe hypertension in pregnancy. There was significant difference in time taken for target blood pressure, decrease of diastolic blood pressure and number of patients responding with first dose (i.e. in 20 minutes), and nifedipine faired better than labetalol. Labetalol at present is more expensive, needs to be administered intravenously, but advantageous in delirious and unconcious patients. Nifedipine is cheaper, easily administrable orally, but not suitable in unconscious patients and nifedipine has slightly more side effects and their long term safety in antenatal period is yet to be determined. However the total number of patients is small in our study and further trial needs to be undertaken to assess the effects on fetal and maternal circulation.

\section{References}

1. Cunningham FG,Lenovo KJ,Bloom SL, Hauth JC,Rouse DJ,Spong CY,section7 obstetrical complications. Hypertensive Disorders of pregnancy.In:Twickler D, Wendel et all, editors Williams obstetrics, $23^{\text {rd }}$ edition, New York: McGraw- Hill Medical Publushing division;2010 ;706711.

2. Duley L.The global effect of pre-eclampsia and eclampsia. Seminars in Perinatology, 2009 jun;33(3):130-137.

3. Steegers EA,von Dadelszen P,Duvkot JJ, Pijnenborg R.Pre-eclampsia. Lancet, 2010,21;376(9741):631-44 
4. Dolea C,AbouZahr C. WHO evidence and information for policy. Global Burden of hypertensive disorders of pregnancy in year 2000;1-2

5. National High Blood Pressure Education Programme Working Group on high blood pressure in pregnancy.Am $\mathbf{J}$ Obstet Gynacol 2000;183:S1-S22.

6. Sathya Lakshmi S,Dasari P . Oral nifedipine versus intravenous labetalol in hypertensive urgencies and emergencies of pregnancy. A Randomized Clinical Trial. Obstet Med Dec 2012 Vol.5.no 4;171-175.

7. Dhali $B$ et al.Intravenous labetalol and oral nifedipine in severe pregnancy induced hypertension.A randomised trial.Int $\mathrm{J}$ Report Contracept Obstet Gynecol.2012 Dec; $1(1): 42-46$

8. Raheem IA,Saaid R,Omar SZ,Tan PC.Oral nifedipine versus intravenous labetalol for acute blood pressure control in hypertensive emergencies of pregnancy:a randomized trial.BJOG 2011; DOI:10.1111/j.1471-0528.2011.03151.x.

9. ACOG. Diagnosis and management of preeclampsia and eclampsia. ACOG Practice Bulletin No. 33, American College of Obstetricians and Gynecologists. Obstet Gynecol 2002 ; 99 : 159 - 67.

10. Duley L. Maternal mortality associated with hypertensive disorders of pregnancy in Africa, Asia, Latin America and the Caribbean. Br. J. Obstet Gynaecol 1992 ; 99 : 547 - 53.

11. Sibai BM, Frangieh AY. Management of severe preeclampsia. Curr Opin Obstet Gynecol $1996 ; 8: 110$ - 3.

12. Magee LA. Elran E, Bull SB, Logan LA, Korean G. Risks and benefits of betareceptive blockers for pregnancy hypertension : overview of the randomized trials. Eur J Obstet Gynecol Reprod Biol $2000 ; 88: 15-26$.
13. Scardo JA, Vermillion ST, Newman RB, Chauhan SP, Hogg BB. A randomized, double blind, hemodynamic evaluation of nifedipine and labetalol in preeclamptic hypertensive emergencies. Am. J. Obstet Gynecol. 1999 ; 181 : 862-6.

14. Wachter RM. Symptomatic hypotension induced by nifedipine in the acute treatment of severe hypertension. Arch Intern Med. 1987 ; 147 : 556 - 58.

15. O' Malia JJ, Sander GE, Giles TD. Nifedipine associated myocardial ischemia or infarction in the treatment of severe hypertension. Arch Intern Med. 1987; 147: $556-558$. 